Institut für Bauforschung e.V.

\title{
Schadensfälle an
} erdberührten Bauteilen
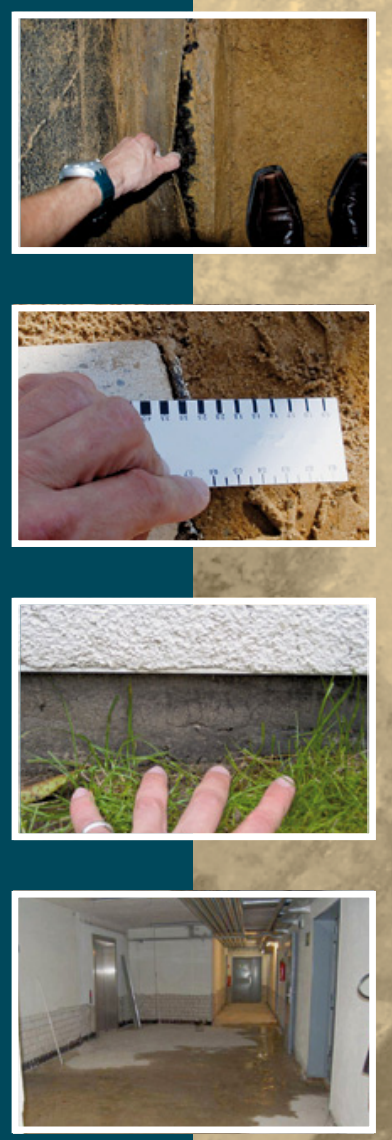

Fraunhofer IRB _Verlag 
Schadensfälle an erdberührten Bauteilen 
https://doi.org/10.51202/9783816786887-1

Generiert durch IP '172.22.53.54', am 26.04.2023, 15:00:50.

Das Erstellen und Weitergeben von Kopien dieses PDFs ist nicht zulässig. 


\section{Institut für Bauforschung e. V. Schadensfälle an erdberührten Bauteilen}

Fraunhofer IRB Verlag 
Bibliografische Information der Deutschen Nationalbibliothek

Die Deutsche Nationalbibliothek verzeichnet diese Publikation in der Deutschen Nationalbibliografie; detaillierte bibliografische Daten sind im Internet über http://dnb.d-nb.de abrufbar.

ISBN (Print): 978-3-8167-8650-4

ISBN (E-Book): 978-3-8167-8688-7

Herstellung: Tim Oliver Pohl

Umschlaggestaltung: Martin Kjer

Druck: freiburger graphische betriebe $\mathrm{GmbH} \&$ Co. KG, Freiburg

Für den Druck des Buches wurde chlor- und säurefreies Papier verwendet.

Alle Rechte vorbehalten

Dieses Werk ist einschließlich aller seiner Teile urheberrechtlich geschützt. Jede Verwertung, die über die engen Grenzen des Urheberrechtsgesetzes hinausgeht, ist ohne schriftliche Zustimmung des Fraunhofer IRB Verlages unzulässig und strafbar. Dies gilt insbesondere für Vervielfältigungen, Übersetzungen, Mikroverfilmungen sowie die Speicherung in elektronischen Systemen.

Die Wiedergabe von Warenbezeichnungen und Handelsnamen in diesem Buch berechtigt nicht zu der Annahme, dass solche Bezeichnungen im Sinne der Warenzeichen- und Markenschutz-Gesetzgebung als frei zu betrachten wären und deshalb von jedermann benutzt werden dürften.

Sollte in diesem Werk direkt oder indirekt auf Gesetze, Vorschriften oder Richtlinien (z. B. DIN, VDI, VDE) Bezug genommen oder aus innen zitiert werden, kann der Verlag keine Gewähr für Richtigkeit, Vollständigkeit oder Aktualität übernehmen. Es empfiehlt sich, gegebenenfalls für die eigenen Arbeiten die vollständigen Vorschriften oder Richtlinien in der jeweils gültigen Fassung hinzuzuziehen.

(C) by Fraunhofer IRB Verlag, 2012

Fraunhofer-Informationszentrum Raum und Bau IRB

Nobelstr. 12, 70569 Stuttgart

Telefon (07 11) 970-2500

Telefax (07 11) 970-2508

E-Mail: irb@irb.fraunhofer.de

http://www.baufachinformation.de 


\section{Inhaltsverzeichnis}

$1 \quad$ Technische Grundlagen $\ldots \ldots \ldots \ldots \ldots \ldots \ldots \ldots \ldots$

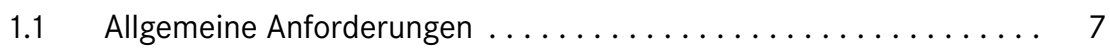

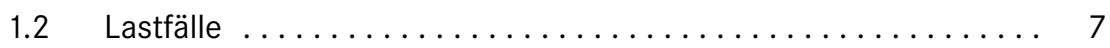

1.3 Abdichtungssysteme .................... 8

1.4 Normen, Regeln und Merkblätter ................. 10

2 Rechtliche Grundlagen $\ldots \ldots \ldots \ldots \ldots \ldots \ldots \ldots \ldots \ldots$

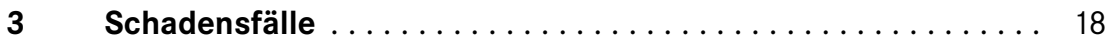

3.1 Mangelhafte Ausführung eines Kellers aus wasserundurchlässigem Beton ............... 18

3.2 Mangelhafte Rampenabdichtung aufgrund Materialunverträglichkeit der eingesetzten Materialien . . . . . . . 24

3.3 Fehlerhafte Ausführung einer Bauwerksabdichtung in der Fläche und im Anschluss an einen Anbau . . . . . . . . . . . 27

3.4 Unzureichender Feuchteschutz eines unterkellerten Einfamilienhauses ..................... 32

3.5 Unsachgemäße Ausführung einer Bauwerksabdichtung mit KMB . . 36

3.6 Mangelhafter Anschluss einer Rohrdurchführung an die Bauwerksabdichtung ................. 43

3.7 Unsachgemäße Ausführung einer Bauwerksabdichtung mit KMB und fehlender Anschluss an die Sohlplatte . . . . . . . . 47

3.8 Einbau eines ungeeigneten Betons für eine Sohlplatte in einem Stallgebäude . . . . . . . . . . . . . . 53

3.9 Fehlerhafte Abdichtung eines Gebäudesockels und Verwendung eines ungeeigneten Sockelputzes . . . . . . . . . . . 57

3.10 Fehlende Bauwerksabdichtung eines Mehrfamilienhauses gegen den Lastfall »drückendes Wasser« . . . . . . . . . 62

3.11 Mangelhaft ausgeführte und ungeeignete nachträgliche Bauwerksabdichtung eines unterkellerten Gebäudes . . . . . . . . 70

3.12 Ungeeignete Bauwerksabdichtung eines Mehrfamilienhauses infolge mangelhafter Dränung des Baugrundes . . . . . . . 76

3.13 Fehlende Querschnittsabdichtung unter Kellerwänden und unzureichende Dränung bei einem Einfamilienhaus . . . . . 81

3.14 Mangelhafte Vorbereitung des Untergrundes und unzureichende Durchtrocknung einer Bauwerksabdichtung mit KMB ....... 86 
3.15 Fehlende Wärmedämmung und unzureichende Bauwerksabdichtung eines nachträglich ausgebauten Kellergeschosses . . . . . . . . 92

4 Schadenprophylaxe ...................... 99

$4.1 \quad$ Untersuchungen und Nachweise . . . . . . . . . . . . 99

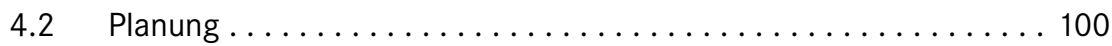

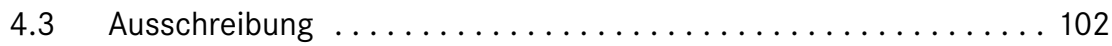

4.4 Ausführungsvorbereitung und Ausführung . . . . . . . . . 103

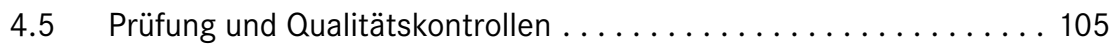

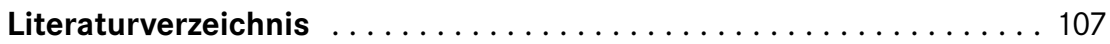

Stichwortverzeichnis . . . . . . . . . . . . . . . . . . . . . 108 